\title{
UM ESTUDO COMPARATIVO ENTRE OS MODELOS DE INSTALAÇÃO E CONSOLIDAÇÃO DAS INDÚSTRIAS AERONÁUTICAS BRASILEIRAS E CANADENSES
}

\section{COMPARATIVE STUDY BETWEEN THE INSTALLATION AND CONSOLIDATION MODELS OF BRAZILIAN AND CANADIAN AERONAUTICAL INDUSTRIES}

\author{
José Fernando Touguinha de Almeida \\ Empresa Brasileira de Aeronáutica - Taubaté - SP - Brasil \\ Edson Aparecida de Araujo Querido Oliveira \\ Universidade de Taubaté - Taubaté - SP - Brasil \\ Marcela Barbosa de Moraes \\ Universidade de Taubaté - Taubaté - SP - Brasil
}

\begin{abstract}
Resumo: No atual cenário econômico mundial, altamente competitivo e globalizado, as indústrias introduziram significativas mudanças nas estruturas organizacionais, principalmente aquelas dependentes de alta tecnologia, remodelando suas estratégias de negócio e redefinindo os modelos de parcerias com a cadeia produtiva e a rede de clientes. Nesse novo contexto econômico, as transferências de tecnologia se transformaram em um importante diferencial competitivo para as indústrias com base tecnológica, permitindo a especialização das empresas nos seus segmentos de atuação. Alguns modelos de transferência de tecnologia foram propostos e adotados mundialmente pelas indústrias, e o setor aeronáutico foi um dos que implementaram esses modelos e que mais evoluíram na busca do modelo colaborativo ideal, formando clusters e arranjos produtivos locais para consolidar e fortalecer os resultados. $O$ objetivo desta pesquisa é discutir os modelos de instalação e consolidação adotados pelas indústrias aeronáuticas canadense e brasileira, identificando suas diferenças e similaridades. Para tanto, a metodologia baseou-se na utilização da abordagem qualitativa e de pesquisa documental. Com essa abordagem foi possível realizar uma análise completa e detalhada dos modelos de instalação e consolidação adotados pelas indústrias aeronáuticas brasileira e canadense. Os resultados apontam que, embora as duas principais empresas montadoras de aeronaves brasileira e canadense atuem no mesmo segmento da aviação regional, a formação das indústrias aeronáuticas
\end{abstract}


brasileira e canadense se deu de maneira diferente, justificando o distinto estágio tecnológico em que se encontram atualmente.

Palavras-chave: Planejamento. Desenvolvimento. Tecnologia. Indústria Aeronáutica.

Abstract: In the current worldwide economic scenario highly competitive and globalized, the industries introduced significant changes in their organizational structures, especially the industries dependent on high technology, reorganizing their business strategies and redefining the models of partnerships with the supply chain and customer network. In this economic context the transfer of technology has become an important competitive advantage to the industries based on high technology, allowing the specialization of those industries in their business segments. Some models of technology transfer have been proposed and worldwide adopted by the industries, being the aeronautic sector one of the sectors that have implemented these models which has more evolved in the pursuit of ideal collaborative model, creating clusters to consolidate and strengthen these results. The objective of this research is to discuss models of installation and consolidation adopted by the Canadian and Brazilian aeronautic industries, identifying differences and similarities. For this purpose, the methodology was based on the use of qualitative approach, adopting the type of documental research. With this approach it was possible to conduct a complete and detailed analysis of models of installation and consolidation adopted by the Brazilian and Canadian aviation industries. The results suggest that, although the main aircraft companies Brazilian and Canadian operating in the same segment of the regional aviation, the Brazilian and Canadian aeronautical industries were consolidate in different ways, justifying the distinct technological stage that they are nowadays.

Keywords: Planning. Development. Technology. Aeronautical Industry.

\section{INTRODUÇÃO}

As transformações do mercado econômico mundial, geradas principalmente em função da intensificação da globalização das últimas décadas e da evolução tecnológica, têm alterado rapidamente o cenário empresarial mundial, criando um mercado cada vez mais competitivo e sem fronteiras.

Conforme Bernardes (2000), nesse novo cenário competitivo mundial, as empresas, e principalmente as indústrias dependentes de alta tecnologia com alto nível de sofisticação tecnológica e longo ciclo de desenvolvimento e maturação de projetos, introduziram significativas mudanças organizacionais e desenvolveram novas estratégias de negócios, reestruturando suas cadeias produtivas com o objetivo de reduzir custos e tornar os processos produtivos mais ágeis e confiáveis. 
Ainda segundo a abordagem de Bernardes (2000), no caso das empresas que trabalham em projetos com longos ciclos de desenvolvimento, e que são dependentes de alta tecnologia, como no caso das indústrias do setor aeronáutico, a formação de redes e parcerias integradas com prestadores de serviço e fornecedores de equipamentos e materiais têm se mostrado uma excelente alternativa em busca de uma cadeia produtiva mais eficiente e com menor custo.

Para Oliveira (2005), o processo de reestruturação da cadeia produtiva adotado pelas indústrias, aplicando a estratégia de integração vertical, é baseado, principalmente, na descentralização do processo produtivo e na transferência de tecnologia das empresas motrizes para os seus fornecedores.

O modelo de cadeia produtiva verticalizada atribuiu às empresas novos conceitos de relacionamento e integração, criando novas redes baseadas na cooperação, e estabelecendo parcerias e alianças em busca do desenvolvimento conjunto dos projetos, assumindo também seus riscos. Esse modelo evidenciou-se, inicialmente, no setor automobilístico, e posteriormente migrou para outros setores produtivos, atingindo também as indústrias aeronáuticas (BASTOS, 2006).

De acordo com Rosenberg (1982), a cadeia produtiva aeronáutica assume, nesse contexto, algumas características próprias que impactam diretamente no processo de transferência de tecnologia. O setor é considerado estratégico para a soberania de um país, e as transferências tecnológicas são geralmente influenciadas por políticas governamentais que fiscalizam e restringem as transferências para outros países.

Para Choi e Rossetti (2005), as empresas fabricantes de aeronaves contratam cerca de $70 \%$ do valor total adicionado de seus produtos diretamente da sua rede de fornecedores ou parceiros. Neste contexto a transferência de tecnologia assumiu um papel estratégico, remodelando as relações dentro da cadeia produtiva das empresas. Em alguns casos, as tecnologias que inicialmente foram desenvolvidas pelas fabricantes de aeronaves foram posteriormente transferidas para a rede de fornecedores, em um processo de terceirização e formação de parcerias.

De acordo com Cassiolato et al (2002), as duas maiores indústrias montadoras de aeronaves para a aviação regional, brasileira e canadense, estão baseadas dentro do mesmo segmento aeronáutico e 
produzem aeronaves voltadas para a aviação comercial regional disputando o mesmo nicho de mercado.

Em função dessa atuação dentro do mesmo segmento aeronáutico; da reestruturação da cadeia produtiva imposta pelas grandes empresas montadoras de aeronaves para reduzir o número de fornecedores; e da descentralização regional da rede de fornecedores, estudar e conhecer os modelos de instalação e consolidação adotados pela indústria aeronáutica brasileira e pela canadense pode transformar-se em um importante diferencial estratégico na consolidação dessas indústrias no mercado mundial.

Dado esse contexto, o objetivo deste trabalho é estudar e discutir os modelos de instalação e consolidação adotados pela indústria aeronáutica brasileira e pela canadense, identificando as suas diferenças e similaridades, no sentido de contribuir para o crescimento da participação da indústria brasileira na cadeia produtiva aeronáutica brasileira e mundial.

\section{REFERENCIAL TEÓRICO}

Segundo Oliveira (2005), para manterem-se competitivas, as indústrias aeronáuticas têm buscado a formação de parcerias com a sua rede de fornecedores e prestadores de serviço, transferindo para essa rede a responsabilidade pelos investimentos em pesquisa, desenvolvimento e inovação dos equipamentos e sistemas utilizados nos projetos aeronáuticos. A transferência de tecnologia pode assumir um importante papel nesse processo, viabilizando a absorção do conhecimento e das técnicas produtivas necessárias para garantir essa relação de parceria.

Oliveira (1998) destaca, ainda, a importância indireta desse segmento para o desenvolvimento de outros setores da economia, em decorrência da capacitação dos profissionais do setor aeronáutico em várias outras áreas tecnológicas.

Sabato (1972) destaca que a tecnologia é uma das principais manifestações da capacidade criadora do homem, e além de fator de produção, ao lado do capital, do trabalho e das matérias-primas, é uma mercadoria que pode ser produzida, distribuída, importada e exportada, possuindo valor de troca e associação de um preço de mercado para a 
sua comercialização, com características de uma autêntica commodity of commerce.

Barbieri (1990) destaca que, apesar de ser tratada como uma mercadoria, a tecnologia assume características próprias, que impossibilita uma comparação rigorosa entre uma tecnologia e outra, caso existam, dificultando o estabelecimento de um parâmetro de preço para as tecnologias inovadoras.

No sentido de mercadoria ou produto comercializável, a tecnologia assume diferentes formas. Cysne (2005) afirma que, como produto, a tecnologia pode se apresentar no formato de um produto tecnológico como forma tangível; por meio de um processo tecnológico como método intangível; em um tipo incorporado no outro tangível e intangível ao mesmo tempo, ou por um modelo conceitual pronto para produção pelo conhecimento, expresso como patentes, resultados de pesquisas, documentações, manuais e relatórios.

Rosenberg (1982) afirma que as tecnologias são mais do que pedaços soltos de maquinaria funcionando no interior das sociedades, e que não existem individualmente: são dependentes de tecnologias complementares, interagindo umas com as outras de forma transparente para um observador casual e, frequentemente, também para os especialistas das tecnologias principais.

Ao utilizar o conceito de tecnologias complementares, Rosenberg (1982) argumenta que uma nova tecnologia que reduza o custo da geração de energia elétrica, por exemplo, afetará diretamente, de diferentes formas, tanto o setor produtivo industrial como também diversas outras áreas da economia. Essa complementaridade entre as tecnologias é fundamental para o processo de inovação. A inovação de uma determinada tecnologia poderá alavancar um processo de inovação das tecnologias complementares que, por sua vez, poderá impulsionar também um processo de inovação das tecnologias complementares, e assim por diante.

Para os países menos desenvolvidos e que iniciaram o seu processo de industrialização depois dos mais desenvolvidos, a transferência de tecnologia constitui-se em um método viável que possibilita reduzir a diferença e a dependência tecnológica. Furtado (1974) enfatiza que esse processo fica mais evidente quando os países subdesenvolvidos iniciaram o processo de substituição das importações, produzindo para 
o mercado interno aquilo que vinham importando dos países mais desenvolvidos.

Nesse ponto do processo de industrialização, segundo Furtado (1974), os países menos desenvolvidos estabeleceram acordos de cooperação e a transferência de tecnologia passou a ser solicitada pelos países periféricos. Efetivou-se como a forma mais fácil de contornar os obstáculos que se apresentaram à industrialização retardada, com o objetivo de colocar os países periféricos em um nível técnico similar ao que apresenta os países cêntricos, detentores das tecnologias mais avançadas.

Segundo Longo (1978), a verdadeira transferência de tecnologia só ocorre quando o receptor consegue absorver todo o conjunto de conhecimentos envolvidos no processo, a ponto de permitir a criação de uma nova tecnologia. Para que isso ocorra, é necessário que o fornecedor da tecnologia se disponha a ceder o seu conjunto de conhecimentos, processos e equipamentos, e o comprador tenha uma equipe técnica capacitada para absorver a nova tecnologia.

O autor cita ainda que, à medida que o receptor segue absorvendo a nova tecnologia, vai adquirindo condições de adaptá-la às suas condições locais, para, em seguida, iniciar o processo de aperfeiçoamento e depois, de inovação.

Segundo Barbieri (1990), a transferência de tecnologia pode ser entendida como o resultado de um processo pelo qual uma empresa passa a dominar todo o conjunto de conhecimentos que constitui uma tecnologia que ela não produziu, e o simples fato de aprender a utilizar uma nova tecnologia não pode ser considerado um processo de transferência de tecnologia. Nesse caso trata-se somente de um processo de difusão da tecnologia. O completo domínio da nova tecnologia é fundamental para que a empresa receptora se torne independente e não precise apelar para a empresa fornecedora quando for preciso modificar, adaptar ou desenvolver uma nova tecnologia a partir da tecnologia transferida.

Rosenberg (1982) destaca que as transferências de tecnologia não constituem fenômenos recentes, já que foram registradas ao longo de toda a história da humanidade com abundantes e convincentes evidências arqueológicas, demonstrando seu aspecto importante também entre as sociedades pré-históricas. 
Conforme Bastos (2006), as empresas fabricantes de aeronaves têm buscado, nas últimas décadas, a redução dos custos dentro da sua cadeia produtiva e de novos projetos, readequando as margens financeiras para, principalmente, aumentar a competitividade dos seus produtos.

Para o autor, essas mudanças impactaram profundamente os fornecedores da indústria aeronáutica que tiveram que adaptar-se e reestruturar-se frente a esse novo cenário imposto pelas indústrias integradoras. Uma das principais mudanças que impactaram diretamente na cadeia de fornecedores foi, sem dúvida, a redução do número de fornecedores diretos da indústria motriz aeronáutica.

Oliveira (2005) destaca que esse número sofreu uma redução significativa na última década, como consequência da busca por fornecedores comuns e pela especialização nos segmentos de atuação por parte das integradoras, delegando aos seus fornecedores diretos a responsabilidade das atividades de desenvolvimento, evolução tecnológica e integração dos subsistemas, caracterizando, assim, um processo de transferência de tecnologia.

Para Bastos (2006), os produtos relacionados ao setor aeronáutico apresentam um alto valor agregado e, em função dos longos ciclos de desenvolvimento, seus projetos são fortemente afetados pela economia mundial. Os investimentos em pesquisa, inovação, desenvolvimento tecnológico e melhoria dos processos produtivos são fundamentais para garantir a sobrevivência e a continuidade econômica das empresas do setor.

Ainda segundo Bastos (2006), a indústria aeronáutica caracterizase pela produção de bens com alto valor agregado e pela geração de empregos especializados e altamente qualificados, principalmente nas áreas de engenharia e de serviços técnicos. A constante evolução dos processos produtivos e da tecnologia utilizada contribui, também, para a evolução de diversos outros produtos, proporcionando a adoção da tecnologia desenvolvida para o setor aeronáutico em outras cadeias produtivas.

De acordo com Oliveira (1998), por ser um setor ligado diretamente à área militar, também é considerado estratégico para a soberania do país, e por permitir uma relativa autonomia e autossuficiência, em 
relação aos projetos e produtos fabricados para as forças armadas, é fortemente mantido por políticas de incentivos governamentais.

$\mathrm{Na}$ atualidade, o setor voltado à fabricação de aeronaves para a aviação comercial é dominado por quatro grandes empresas: duas fabricantes de aviões de grande porte, a americana Boeing e a europeia Air Bus, e duas fabricantes voltadas à produção de jatos regionais ou médio porte (commuters), a Empresa Brasileira de Aeronáutica Embraer, e a canadense Bombardier (OLIVEIRA, 2005).

De acordo com Amato Neto e Santos (2005), Bernardes (2000) e Lima et al. (2005), o desenvolvimento da indústria aeronáutica brasileira pode ser divido em três períodos:

- primeiro: início na década de 1930;

- segundo: final da década de 1940; e

- terceiro: final da década de 1960.

Para os autores, esses três períodos apresentaram características distintas e foram decisivas para o desenvolvimento da indústria aeronáutica brasileira.

Segundo os autores Amato Neto e Santos (2005), Bernardes (2000) e Lima et al. (2005), é na década de 1930 que tem início o primeiro período de desenvolvimento da indústria aeronáutica brasileira. Nesse período, a base produtiva das empresas era totalmente dependente de encomendas governamentais e a maioria das aeronaves civis era comprada pelo Governo para distribuição aos aeroclubes.

O segundo período que iniciou no final da década de 1940, de acordo com os autores Amato Neto (2005), Bernardes (2000) e Lima et al (2005), foi caracterizado por uma maior ação do Governo no sentido de planejar o desenvolvimento profissional especializado para o setor aeronáutico.

O terceiro período divide-se em duas fases: a primeira denominada pré-privatização e a segunda pós-privatização: a fase anterior e a posterior à privatização da empresa brasileira montadora de aeronaves, respectivamente.

De acordo com o levantamento realizado pela Aerospace Industries Association of Canada (AIAC, 2009), a indústria aeroespacial canadense é composta por mais de 400 empresas e é considerada a quinta maior indústria aeroespacial do mundo, atrás dos Estados Unidos, França, 
Reino Unido e Alemanha e estão relativamente distribuídas por todo o território, desde a costa do Atlântico até o Pacífico, porém, aglomerando-se em dois principais centros produtivos, Montreal e Toronto.

Um dos principais centros está localizado em Montreal, Quebec, que concentra aproximadamente 240 empresas aeronáuticas, incluindo 20 das principais integradoras e fabricantes de equipamentos e mais de 200 fornecedores de sistemas, equipamentos e prestadores de serviços.

O segundo centro aeronáutico canadense mais importante está localizado no Estado de Ontário, com empresas instaladas, principalmente, no sudeste do território, desde Ottawa até Windsor, com uma concentração maior em torno de Toronto. De acordo com o relatório da OSEC (2012) o centro aeronáutico de Ontário é responsável pelo emprego direto de cerca de 20.000 profissionais de várias especialidades. Ainda segundo o relatório da OSEC, o polo aeronáutico de Ontário apresenta um faturamento anual estimado em aproximadamente US\$ 6.5 bilhões de dólares.

De acordo com Emerson (2012), no ano de 2010, a indústria aeronáutica canadense exportou $73,1 \%$ do total da sua produção, o equivalente a $\$ 15.3$ bilhões de dólares, sendo que $59,9 \%$ desse total, o equivalente a US\$ 9.2 bilhões de dólares, foram comercializados com o mercado norte americano.

Dentro do cenário das indústrias que compõem o segmento aeronáutico canadense, a Bombardier se destaca como a maior montadora de aeronaves e é considerada uma das principais indústrias canadenses do segmento, junto com a fábrica de motores Pratt \& Whitney e as montadoras de helicóptero Bell Helicopter Textron e a Eurocopter. A empresa possui duas unidades produtivas no território canadense, uma em Montreal e outra em Toronto. A Bombardier está focada, principalmente, no setor da aviação regional e é a maior competidora da montadora de aeronaves brasileira Embraer nesse segmento.

As indústrias aeronáuticas brasileiras, que é considerada a maior do hemisfério sul, tem o seu centro produtivo concentrado na Região Metropolitana do Vale do Paraíba e Litoral Norte. Moraes (2014) evidenciou que, no Brasil, principalmente nas cidades de São José dos Campos, Taubaté e Caçapava, todas situadas no Estado de São Paulo, há 
330 Pequenas e Médias Empresas - PMEs do setor aeronáutico. A autora evidencia ainda que há mais dois centros produtivos de menor amplitude localizados em Gavião Peixoto e Botucatu, ambos localizados no Estado de São Paulo.

De acordo com a Associação das Indústrias Aeroespaciais do Brasil - AIAB (2012), esse setor opera de forma globalizada competindo no mercado mundial, posicionando-se como líder em vários segmentos de mercado, graças ao domínio tecnológico e a qualidade de seus produtos. As empresas que formam esse Parque Industrial atuam desde a concepção até o suporte pós-venda dos itens por ela produzidos, além de prestarem diversos tipos de serviços especializados.

\section{MÉTODOS E PROCEDIMENTOS}

A escolha de uma metodologia adequada à linha da pesquisa proposta no trabalho, com procedimentos e métodos claros, sustentados cientificamente, delimitando o seu objetivo e estabelecendo o seu fim, é fundamental para embasar o conteúdo e prover a credibilidade acadêmica à pesquisa proposta. De acordo com Menezes e Silva (2005, p. 9), a metodologia da pesquisa tem como função "mostrar ao pesquisador como andar no 'caminho das pedras' da pesquisa", ajudá-lo a refletir e instigar um novo olhar sobre o mundo: um olhar curioso, indagador e criativo.

Os procedimentos e os métodos adotados pelo pesquisador para conduzir cientificamente a pesquisa devem estar necessariamente alinhados e de acordo com o objetivo proposto, definindo o desenvolvimento da pesquisa, além de servirem de suporte na condução dos trabalhos (MARCONI; LAKATOS, 2005). Segundo Vergara (2005), pode-se considerar a caracterização da pesquisa a partir de três critérios básicos: quanto aos seus objetivos; quanto aos procedimentos técnicos e quanto à forma de abordagem.

Esta pesquisa, quanto aos objetivos, assume características exploratória e descritiva. De acordo com Menezes e Silva (2005), o estudo exploratório visa a proporcionar uma maior familiaridade com o problema proposto para torná-lo explícito ou construir hipóteses. Do ponto de vista dos procedimentos técnicos, este estudo baseia-se em pesquisa bibliográfica e documental. Seguindo os conceitos de Marconi 
e Lakatos (2005), esta pesquisa é elaborada a partir de materiais já publicados em livros, artigos de periódicos e trabalhos acadêmicos, incluindo os disponibilizados na internet. A pesquisa documental é elaborada a partir de materiais que não receberam tratamento analítico.

Em relação à natureza a pesquisa é aplicada, pois, de acordo com os conceitos de Menezes e Silva (2005), esta pesquisa tem o objetivo de gerar dados e informações com aplicação prática, orientada à identificação de interesses locais. Os dados disponíveis para a análise e discussão do problema, obtidos pelo processo de levantamento e pesquisa, permitiram uma abordagem quali-quantitativa à pesquisa, proporcionando tanto análises subjetivas como também estatísticas e quantificáveis.

Por tratar-se de uma pesquisa exploratória, utilizaram-se, como formas principais de coleta de dados, as pesquisas documental e a bibliográfica, feitas em documentos, livros e material disponibilizado na internet, em websites de instituições acadêmicas, como universidades, bases de periódicos da Coordenação de Aperfeiçoamento de Pessoal de Nível Superior - CAPES, indexadores de artigos e trabalhos acadêmicos como o SCIELO, sistemas de busca como o Google Acadêmico, câmaras de comércio e entidades não governamentais relacionadas à indústria aeroespacial mundial.

\section{DISCUSSÃO DOS DADOS E ANÁLISE COMPARATIVA}

O setor aeroespacial caracteriza-se pela necessidade constante de um alto investimento em atividades de pesquisa e desenvolvimento, com o objetivo de estimular a inovação tecnológica e a evolução contínua dos produtos. Além disso, o setor contribui para o aumento da capacitação profissional do País, gerando empregos altamente especializados com alta graduação acadêmica. Essas são características que se fazem presentes, principalmente, nos setores que empregam alta tecnologia em seus produtos e processos produtivos, como, por exemplo, o segmento aeronáutico.

Além de compensar 0 alto grau de obsolescência tecnológica, principalmente dos sistemas embarcados, de acordo com Pinheiro e Silva (1998), os investimentos em pesquisa e inovação realizados pelo setor aeronáutico tornam-se um diferencial estratégico na busca por 
produtos e processos com custo produtivo mais baixo e com maior nível de qualidade e confiabilidade, principalmente em um mercado tão competitivo como é o aeronáutico.

Os efeitos desencadeados por esses investimentos, também, promovem o desenvolvimento de outros setores da indústria. $O$ desenvolvimento de processos produtivos e as inovações tecnológicas são transferidos para outras indústrias, contribuindo para o seu desenvolvimento e fortalecimento, assim como para o desenvolvimento regional, segundo Francisco (2009), na medida em que as transferências das novas tecnologias fluem para a rede de fornecedores locais da empresa geradora dessa nova tecnologia.

Esse cenário pode ser constatado pelo polo tecnológico aeroespacial, estabelecido no Município de São José dos Campos. Com vocação e origem agropecuária, na década de 1950 a cidade recebeu a instalação de um centro de pesquisa e de um instituto tecnológico voltados para o segmento aeronáutico, fatos que contribuíram para a instalação de uma empresa estatal fabricante de aeronaves que foi privatizada posteriormente, pelo governo brasileiro, tornando-se hoje a terceira maior fabricante de aeronaves do mundo.

A instalação de uma indústria fabricante de aeronaves em São José dos Campos contribuiu para o desenvolvimento econômico do setor no município, conforme afirmação de Amato Neto (2009), viabilizando o surgimento de médias e pequenas empresas que constituem à rede de fornecedores locais da maior montadora nacional de aeronaves. Atualmente, o município é reconhecido mundialmente como um importante centro formador de profissionais para o segmento aeronáutico, e também como o principal polo aeroespacial do hemisfério sul.

Com o propósito de estimular o desenvolvimento regional com o fortalecimento da indústria aeronáutica brasileira, o objetivo principal deste estudo foi traçar um estudo paralelo entre essa indústria e a canadense, levantando as bases históricas de suas criações, os processos e as metodologias de consolidação adotadas, identificando suas similaridades e diferenças.

A pesquisa foi desenvolvida por levantamento bibliográfico sob a perspectiva dos conceitos e definições referentes à tecnologia e aos processos de transferência de tecnologia. Durante a elaboração deste 
estudo, alguns pontos históricos foram utilizados para descrever a formação da indústria aeronáutica brasileira e da canadense. Além disso, foram abordadas características importantes relacionadas ao mercado aeronáutico mundial, com o objetivo de contextualizá-lo em função dessas indústrias.

Embora não tenha sido encontrado um grande volume de informações públicas referentes a indústria aeronáutica canadense, acredita-se ter alcançado o objetivo proposto neste artigo. Os dados levantados mostraram-se confiáveis e suficientes para permitir a discussão proposta e responder os problemas apresentados, conforme expostos a seguir.

Ainda que as duas principais empresas fabricantes de aeronaves, a brasileira e a canadense, atuem no mesmo segmento de mercado, que é o da montagem de aeronaves voltadas para a aviação regional, suas participações dentro do cenário produtivo e de desenvolvimento das respectivas indústrias aeronáuticas mostram-se bem distintas.

A indústria aeronáutica brasileira se caracteriza por um processo de industrialização tardia em relação aos países economicamente mais desenvolvidos e tecnologicamente mais avançados. Como consequência dessa defasagem, a indústria aeronáutica brasileira iniciou suas atividades alguns anos mais tarde, em relação aos países mais desenvolvidos, e foi fundamentada, principalmente, pela ação da iniciativa privada, pela falta de planejamento para capacitação de mão de obra especializada e pela alta dependência dos pedidos e subsídios do Governo brasileiro para o setor.

A falta de estratégia para a fundamentação de uma indústria aeronáutica ficou evidente nas fábricas de Lagoa Santa e do Galeão, conforme destacam os autores Amato Neto e Santos (2005), Bernardes (2000) e Lima et al. (2005), que foram criadas com base na produção de aeronaves para o governo brasileiro, sob licença de empresas americanas e alemãs, concorrendo com a CPA e a Companhia Nacional de Navegação Aeronáutica - CNNA e sem que tenham sido realizados acordos para a transferência de tecnologia para a capacitação dos profissionais brasileiros.

A análise desses dados demonstra que o processo para a instalação, consolidação e transferência de tecnologia, adotado pelo governo para a formação da indústria aeronáutica brasileira, baseou-se 
na criação de várias empresas integradoras de aeronaves, porém sem preocupar-se em estabelecer medidas para que a tecnologia para produzir as aeronaves pelas empresas nacionais fosse absorvida.

Somente após a criação do ITA, do CTA e da Embraer, o governo brasileiro fundamentou a indústria aeronáutica brasileira em uma única empresa montadora de aeronaves e desenvolveu a competência nacional para a área de projetos de aeronaves, mas baseou o desenvolvimento da rede de fornecedores em médias e pequenas empresas. A estratégia não se mostrou eficiente novamente, pois as médias e pequenas empresas têm como característica principal uma dependência maior à estabilidade econômica e às políticas governamentais.

A origem da indústria aeronáutica canadense também foi baseada na ação intensa de o Governo canadense manter subsídios e realizar encomendas de aeronaves militares, porém suas ações foram mais efetivas e sustentaram um desenvolvimento mais equilibrado.

Os produtos foram diversificados entre as diversas áreas aeronáuticas, não se restringindo apenas a empresas fabricantes de aeronaves, como, por exemplo, a Pratt $\&$ Whitney e a CAE, líderes dos seus segmentos no mercado mundial. Na atualidade, tanto a fabricante de aeronaves brasileira como a canadense ainda recebem incentivos fiscais dos seus governos para manterem-se competitivas. Como consequência destes subsídios, os governos brasileiro e canadense envolveram-se em disputas judiciais na Organização Mundial do Comércio - OMC.

Entretanto, a indústria aeronáutica canadense mostra-se mais estável do que a brasileira. Os dados levantados possibilitaram verificar uma recuperação mais rápida do setor aeronáutico canadense, após a crise econômica de 2008, quando retomou a tendência de crescimento e de geração dos postos de trabalho diretos em 2010, enquanto que a indústria aeronáutica brasileira apresentou uma redução dos postos de trabalho diretos no mesmo ano, o que demonstra maior estabilidade do setor aeronáutico canadense em relação ao brasileiro.

Os dados comparativos entre os postos de trabalho diretos anuais da indústria aeronáuticas brasileiras e canadenses estão apresentados na Tabela 1. 
Tabela 1. Postos de trabalho diretos da indústria aeronáutica brasileira e da canadense

\begin{tabular}{l|l|l|l|l}
\hline & 2007 & 2008 & 2009 & 2010 \\
\hline Indústria canadense & 82.000 & $\begin{array}{l}83.000 \\
(+1,21 \%)\end{array}$ & $\begin{array}{l}79.000 \\
(-4,8 \%)\end{array}$ & $\begin{array}{l}81.000 \\
(+2,53 \%)\end{array}$ \\
\hline Indústria brasileira & 25.200 & $\begin{array}{l}27.100 \\
(+7,54 \%)\end{array}$ & $\begin{array}{l}24.000 \\
(-11,4 \%)\end{array}$ & $\begin{array}{l}22.600 \\
(-5,83 \%)\end{array}$ \\
\hline
\end{tabular}

Fonte: AIAB (2012) e AIAC (2010).

A análise comparativa dos dados coletados possibilitou realizar um levantamento da efetividade da política de transferência de tecnologia adotada pela maior empresa integradora de aeronaves brasileira antes e depois do processo de privatização.

Além de concentrar em uma única empresa os projetos aeronáuticos, a criação da maior empresa brasileira fabricante de aeronaves também tinha o objetivo de estimular o desenvolvimento de uma rede de fornecedores que fosse capaz de produzir sistemas e equipamentos para o setor a partir dessa empresa motriz, buscando o fortalecimento da indústria aeronáutica brasileira no cenário mundial.

Os resultados apontam que, durante a fase de pré-privatização, a política de transferência de tecnologia adotada pela maior fabricante de aeronaves brasileira mostrou-se efetiva, estimulando a criação de fornecedores nacionais com um expressivo nível tecnológico. Nessa fase, a quantidade de fornecedores brasileiros chegou a representar $20 \%$ do total de fornecedores dentro de um projeto de aeronave desenvolvido pela empresa motriz brasileira.

$\mathrm{Na}$ fase de pós-privatização, porém, essa política foi alterada. Além da política de adoção de parcerias, a empresa também passou por uma reestruturação organizacional, como consequência, a indústria aeronáutica brasileira entrou em crise.

A fabricante brasileira de aeronaves alterou sua estratégia, focando seus objetivos no lucro, e ocorreu uma redução significativa da quantidade de fornecedores nacionais nesse segmento, inclusive com a compra de várias empresas brasileiras por empresas estrangeiras.

Atualmente, os fornecedores brasileiros concentram suas atividades em produtos com baixo valor tecnológico agregado e intensa 
aplicação de mão de obra. O processo de transferência de tecnologia dentro da indústria aeronáutica brasileira foi reduzido, impondo uma quase estagnação tecnológica da rede de fornecedores nacional.

Nessa fase, a empresa brasileira fabricante de aeronaves estimulou a instalação da sua rede de parceiros no Brasil, com o objetivo de promover novamente o desenvolvimento do setor, porém, a iniciativa não se mostrou eficiente, pois a maioria das empresas que se instalou no país não efetuou a transferência da tecnologia ou do processo produtivo para as instalações das empresas brasileiras.

Conclui-se, portanto, que as políticas de consolidação e de transferência de tecnologia para o desenvolvimento da indústria aeronáutica brasileira se mostraram mais eficazes na fase préprivatização, quando se conseguiu alavancar com mais eficiência a formação de uma rede de fornecedores diversificada e com maior valor tecnológico agregado, embora se mostrasse ainda mais dependente da intervenção do governo brasileiro do que na fase de pós-privatização.

A análise do contexto da indústria aeronáutica canadense aponta um movimento semelhante, que ocorreu com a instalação de várias empresas em solo canadense.

O trabalho foi realizado com mais eficiência, e a diversificação da rede de fornecedores da cadeia produtiva atuou de forma mais consistente, não se restringindo a fornecer sistemas e equipamentos apenas para a fabricante de aeronaves canadense Bombardier, voltando sua produção principalmente para o mercado externo.

Identifica-se, também, a dependência da indústria aeronáutica brasileira em relação à sua principal montadora de aeronaves. Em função, principalmente, do nível tecnológico em que a rede de fornecedores se encontra: as empresas aeronáuticas nacionais não conseguem competir de forma efetiva no mercado mundial, ficando restritas somente ao mercado interno.

Não se observou esse aspecto na indústria aeronáutica canadense, que, além de apresentar uma diversificação do setor e de um nível tecnológico mais avançado em relação ao brasileiro, não se limita a abastecer o mercado interno, destinando aproximadamente $73 \%$ da sua produção para o mercado externo.

O estudo permitiu identificar que a proximidade regional do Canadá em relação ao mercado norte-americano contribuiu de forma 
efetiva para o desenvolvimento da indústria aeronáutica canadense. Além disso, os acordos comerciais entre os dois países mostraram-se ferramentas eficazes, permitindo o acesso das empresas canadenses ao restrito mercado americano em condições de igualdade com as empresas americanas.

Esse cenário demonstra a importância do papel do Estado no sentido de promover os acordos comerciais internacionais. $O$ estabelecimento desses acordos é fundamental para estimular as exportações; desenvolver o nível tecnológico das empresas nacionais; e diminuir a dependência do setor brasileiro, que atualmente restringese, basicamente, a participar da cadeia produtiva da empresa integradora de aeronaves brasileira.

Pôde-se concluir, neste estudo, que, embora a principal indústria fabricante de aeronaves brasileira e a principal canadense atuem no mesmo segmento da aviação regional, os processos de consolidação, de transferência de tecnologia e de capacitação profissional das empresas que constituem a rede de fornecedores foram desenvolvidos de formas distintas, o que resultou na consolidação das duas bases industriais de formas diferenciadas.

No caso canadense a preocupação com a transferência de tecnologia e a capacitação profissional permitiu a implantação de uma base industrial competitiva e diversificada, voltada para o mercado externo, enquanto, no caso do Brasil, o processo foi baseado na consolidação de uma empresa central, responsável pela capacitação profissional, pelo desenvolvimento dos projetos aeronáuticos e pela implementação e sustentabilidade da rede de fornecedores de equipamentos, materiais e sistemas aeronáuticos.

Em função da dependência das ações do Estado nesse setor, o modelo adotado pelo governo brasileiro no desenvolvimento da rede de fornecedores não se mostrou eficiente, porém, para alavancar uma indústria integradora forte, o modelo pode ser considerado eficiente, pois a empresa brasileira, atualmente, é considerada a terceira maior indústria montadora de aeronaves do mundo.

Em comparação, a indústria aeronáutica canadense está fundamentada em várias grandes empresas, consolidada mundialmente. Além disso, a diversidade de produtos fabricados pelos fornecedores 
canadenses e a estabilidade econômica do Canadá permitiram a consolidação desse segmento.

O Quadro 1 apresenta uma síntese das análises comparativas entre a indústria aeronáutica brasileira e a canadense, com base nos dados levantados para esta pesquisa. Com base nos dados analisados e nas discussões apresentadas, embora haja semelhança entre as duas maiores integradoras de aeronaves, é possível concluir que as políticas de consolidação e de transferência de tecnologia adotadas pela indústria aeronáutica canadense se mostraram mais eficientes do que as adotadas pela indústria aeronáutica brasileira. 
Quadro 1. Síntese comparativa da indústria aeronáutica brasileira e da canadense

\begin{tabular}{|c|c|c|}
\hline Descrição & Canadense & Brasileira \\
\hline $\begin{array}{ll}\text { Rede } & \text { de } \\
\text { fornecedores } & \\
\end{array}$ & Foco em grandes players & $\begin{array}{l}\text { Foco em pequenas e médias } \\
\text { empresas }\end{array}$ \\
\hline Regionalização & Descentralizada & Centralizada \\
\hline Mercado & $\begin{array}{l}\text { Voltada para o mercado } \\
\text { externo }\end{array}$ & $\begin{array}{l}\text { Voltada para o mercado interno } \\
\text { (atender a integradora brasileira) }\end{array}$ \\
\hline Segmento & $\begin{array}{l}\text { Voltada para a aviação } \\
\text { comercial regional }\end{array}$ & $\begin{array}{l}\text { Voltada para a aviação comercial } \\
\text { regional }\end{array}$ \\
\hline Produtos e Sistemas & $\begin{array}{l}\text { Diversificada e com } \\
\text { grande valor tecnológico } \\
\text { agregado }\end{array}$ & $\begin{array}{l}\text { Focada em atividades com intensa } \\
\text { agregação de mão de obra e baixa } \\
\text { agregação tecnológica }\end{array}$ \\
\hline $\begin{array}{l}\text { Principal } \\
\text { integradora }\end{array}$ & $\begin{array}{l}\text { Baseada em mais de uma } \\
\text { empresa aeronáutica } \\
\text { privada }\end{array}$ & $\begin{array}{l}\text { Baseada em uma única empresa } \\
\text { aeronáutica privada }\end{array}$ \\
\hline Início das atividades & 1909 & $\begin{array}{l}\text { Primeiro período: } 1935 \\
\text { Consolidação: } 1960 \text { (criação da } \\
\text { Embraer) }\end{array}$ \\
\hline $\begin{array}{l}\text { Postos de trabalho } \\
\text { diretos }(2010)\end{array}$ & 81.000 & 22.600 \\
\hline $\begin{array}{l}\text { Posição ranking } \\
\text { mundial (2008) }\end{array}$ & $5^{\circ}$ lugar & $10^{\circ}$ lugar \\
\hline
\end{tabular}

Fonte: Elaborada pelos autores deste artigo

Além disso, a estratégia adotada pelo governo brasileiro de basear a indústria aeronáutica em médias e pequenas empresas, após a privatização da maior empresa fabricante de aeronaves brasileira, não se mostrou eficiente, com uma tendência de redução do número de fornecedores nacionais, além de reduzir o valor tecnológico agregado em seus produtos e sistemas.

Por fim, com base nos dados apresentados da indústria aeronáutica brasileira, pode-se considerar que as expectativas para o setor aeronáutico, dentro do cenário nacional, mostram-se positivas, embora os fornecedores brasileiros de equipamentos e sistemas aeronáuticos ocupem, atualmente, uma posição de extrema dependência dentro da cadeia produtiva, totalmente inexpressiva em relação à cadeia produtiva aeronáutica mundial. 
A estratégia do governo em criar centros de tecnologia aeronáutica, institutos de pesquisa e instituições acadêmicas, com o objetivo, primeiramente, de absorver o conhecimento por meio dos acordos de transferência de tecnologia internacionais, e posteriormente de capacitar os profissionais brasileiros no setor aeronáutico, mostrouse eficiente, tendo em vista que, atualmente, a maior empresa montadora de aeronaves brasileira está posicionada como a terceira maior empresa fabricante de aeronaves do mundo.

Com base nesse contexto, pode-se afirmar que, com maior investimento, por parte do governo brasileiro para estimular a produção das empresas aeronáuticas nacionais, criando linhas de crédito mais atrativas, incentivos fiscais e ampliando os financiamentos para pesquisa e inovação tecnológica, a qualidade dos profissionais brasileiros será de um nível de capacitação elevado e capaz de gerar produtos e serviços mais especializados do que os produzidos atualmente, com valor tecnológico agregado mais elevado e em condições de competir com os fornecedores aeronáuticos estrangeiros.

\section{CONCLUSÃO}

O estudo mostrou que embora as duas maiores empresas montadoras de aeronaves - a brasileira e a canadense - atuem no mesmo segmento de aviação regional, os modelos de criação e os conceitos adotados pelos dois países para a consolidação e o desenvolvimento de suas indústrias aeronáuticas foram praticados de formas diferentes.

Enquanto a indústria aeronáutica canadense baseou-se na instalação de grandes players internacionais, garantindo que, nesse processo, o domínio da tecnologia fosse transferido para as empresas instaladas no território do Canadá, o modelo brasileiro, desde o início, mostrou-se carente de um planejamento, baseando o desenvolvimento de sua indústria aeronáutica nas pequenas e médias empresas e em uma única grande montadora estatal de aeronaves, responsável por desenvolver os projetos aeronáuticos, que se mostrou relativamente eficiente até o momento da sua privatização.

Os resultados apontam que em um segmento extremamente competitivo e dependente da intervenção do governo, como é o 
aeronáutico, a estratégia brasileira, principalmente após a privatização da maior fabricante de aeronaves, não se mostrou a mais adequada. $\mathrm{O}$ cenário mostrou-se inadequado, também, em função da instabilidade econômica pela qual o País atravessou.

O último aspecto abordado neste trabalho foi o estágio atual das empresas brasileiras que fazem parte da cadeia produtiva aeronáutica. A partir dos dados levantados, foi possível realizar uma análise comparativa do nível tecnológico e da abrangência das empresas brasileiras e das canadenses que atuam como fornecedoras de equipamentos, sistemas e serviços da cadeia produtiva aeronáutica.

Este estudo permitiu identificar a baixa participação das empresas brasileiras na cadeia produtiva aeronáutica, tanto no cenário nacional como no internacional, além de apontar a sua atuação no fornecimento de sistemas com baixo nível tecnológico, que se resumem basicamente a produtos com intenso emprego de mão de obra, o que as caracteriza como fornecedoras de terceiro nível.

Os resultados apontam maior maturidade e qualificação dos fornecedores canadenses, que, em função do domínio da tecnologia aeronáutica, têm sua produção orientada para o mercado externo, produzindo equipamentos, sistemas e serviços com alto valor tecnológico agregado. $O$ processo de transferência de tecnologia pelo qual essas empresas passaram é um dos fatores que contribuiu para que atingissem o estágio atual.

Esta pesquisa, por ser de caráter exploratório, teve como objetivo identificar e discutir os modelos de instalação e consolidação adotados pela indústria aeronáutica brasileira e canadense, não tendo pretensão e nem tampouco subsídios para uma análise mais profunda das causas e motivos do atual estágio dos fornecedores brasileiros da cadeia produtiva aeronáutica, como também das consequências e impactos desse segmento no contexto do desenvolvimento econômico regional.

\section{REFERÊNCIAS}

ASSOCIAÇÃO DAS INDÚSTRIAS AEROESPACIAIS DO BRASIL - AIAB. (2012) Números da Associação das Indústrias Aeroespaciais do Brasil. Disponível em: 
http://www.aiab.org.br/portugues/index.php?option=com_content\&tas $\mathrm{k}=\mathrm{view \& id}=13 \&$ ltemid=26. Acesso em 29 jul. 2012.

AEROSPACE INDUSTRIES ASSOCIATION OF CANADA (AIAC).Canadian Aerospace Industry: performance 2008. Canada, june/2009.

AMATO NETO, J.; SANTOS, I. C. Estratégias para criação da indústria aeroespacial brasileira. Revista Brasileira de Gestão e Desenvolvimento Regional, v. 1, n. 2, p. 16-40, mai-ago/2005.

BARBIERI, J. C. Produção e transferência de tecnologia. São Paulo: Ática, 1990.

BASTOS, C. E. Atributos de parcerias de sucesso em cadeias de suprimentos: um estudo de caso na relação fabricante-fornecedor na indústria aeronáutica. Tese (Mestre em Administração) - Departamento de Administração da Faculdade de Economia, Administração e Contabilidade da Universidade de São Paulo, São Paulo. 2006.

BERNARDES, R. O caso Embraer privatização e transformação da gestão empresarial: dos imperativos tecnológicos à focalização no mercado. In: Cadernos de Gestão Tecnológica. São Paulo: CYTED, PGT/USP, p. 46, 2000.

CASSIOLATO, J. E. et al. Transfer of technology for successful integration into the global economy: a case study of Embraer in Brazil. United Nations; New York and Geneva: UNCTAD/ITE/IPC/Misc.20, 2002.

CHOI, T. Y.; ROSSETTI, C. On the dark side of strategic sourcing: experiences from the aerospace industry. Academy of Management Executive; vol. 19, n. 1, 2005.

CYSNE, F. P. Transferência de tecnologia entre a universidade e a indústria. In: Encontros BIBLI - Revista Eletrônica de Biblioteconomia e Ciência da Informação. Florianópolis: Universidade Federal de Santa Catarina, n. 20, segundo semestre 2005. 
EMERSON, D. L. Aerospace Review: mandated by the government of Canada. february/2012. Disponível em: $<$ http://www.aerospacereview.ca $>$. Acesso em: 01 jul. 2012.

LIMA, J. C. C. O. et al. A cadeia aeronáutica brasileira e o desafio da inovação. BNDES Setorial, Rio de Janeiro, n. 21, p. 31-55, março/ 2005.

LONGO, W. P. Tecnologia e transferência de tecnologia. Revista A Defesa Nacional, 678, 54, Rio de Janeiro, 1978.

MARCONI, M. A., LAKATOS, E. M. Fundamentos de metodologia científica. São Paulo: Atlas, 2005.

MENESES, E. M.; SILVA, E. L. Metodologia da pesquisa e elaboração de dissertação. 4. ed. Florianópolis: Universidade Federal de Santa Catarina, 2005.

MORAES, Marcela Barbosa de. Empreendedorismo Estratégico em Pequenas e Médias Empresas do Setor Aeronáutico Brasileiro e Canadense. 155f. 2014. Tese (Programa de Pós-Graduação em Administração) - Universidade Nove de Julho, São Paulo, 2014.

OLIVEIRA, Edson Aparecida de Araújo Querido. Proposta de modelo organizacional de gestão de tecnologia para o setor espacial brasileiro: estudo do caso VLS. 1998. 360f. Tese (Doutorado em Engenharia Aeronáutica e Mecânica) - Instituto Tecnológico de Aeronáutica, São José dos Campos: Instituto Tecnológico de Aeronáutica, 1998.

OLIVEIRA, L. G. A cadeia de produção Aeronáutica no Brasil: uma análise sobre os fornecedores da Embraer. 2005. Tese (Doutorado em Política Científica e Tecnológica) - Instituto de Geociências. Campinas: Universidade de Campinas, 2005.

OSEC - BUSINESS NETWORK SWITZERLAND. The aerospace industry in Canada. march/2012. Disponível em: <http://aboutus.osec.ch/en>. Acesso em: 17 jun. 2012. 
ROSENBERG, N. Por dentro da caixa preta: tecnologia e economia. First Edition, Press Syndicate of the Universe of Cambridge, 1982. São Paulo: UNICAMP, 2006.

SABATO, J. A. El comercio de tecnologia. Trabalho publicado pelo Programa Regional de Desenvolvimento Científico e Tecnológico, Departamento de Assuntos Científicos da OEA, 1972. In: Ensayos em Campera. Argentina: Universidad Nacional de Quilmes: Editorial, 2004.

VERGARA, S. C. Projetos e relatórios de pesquisa em administração. 6. ed. São Paulo: Atlas, 2005.

Submetido em

Aprovado em

Sobre os autores

José Fernando Touguinha de Almeida

Mestre em Planejamento e Desenvolvimento Regional pela Universidade de Taubaté UNITAU, Analista de Desenvolvimento de Produto da Embraer.

Endereço: Rua Expedicionário Ernesto Pereira, Portão 3, CEP: 12030-320 - Taubaté SP - Brasil.

E-mail: almeida.jose@gmail.com

\section{Edson Aparecida de Araujo Querido Oliveira}

Doutor em Engenharia Aeronáutica e Mecânica e Pós-Doutorado em Gestão da Inovação Tecnológica pelo Instituto Tecnológico de Aeronáutica - ITA, Professor e Coordenador do Mestrado Profissional em Gestão e Desenvolvimento Regional e do Mestrado Acadêmico em Planejamento e Desenvolvimento Regional da Universidade de Taubaté - UNITAU.

Endereço: Rua Expedicionário Ernesto Pereira, Portão 3. 12030-320 - Taubaté - SP Brasil.

E-mail: edsonaaqo@gmail.com

\section{Marcela Barbosa de Moraes}

Doutora em Administração pela Universidade Nove de Julho (UNINOVE). Professora do Mestrado Acadêmico em Planejamento e Desenvolvimento Regional na Universidade de Taubaté (UNITAU).

Endereço: Rua Expedicionário Ernesto Pereira, Portão 3. 12030-320 - Taubaté - SP Brasil.

E-mail: marcelabmoraes@gmail.com 